\title{
Detection of structural heterozygosity and a varied chromosome number in Euphorbia pilosa L. from Kashmir, India
}

\author{
Manjit Inder Singh Saggoo and Umer Farooq ${ }^{1}$ \\ Department of Botany, Punjabi University, Patiala 147 002, Punjab, India \\ ${ }^{1}$ Author for correspondence: (darumer786@gmail.com) \\ Received April 22, 2011; accepted August 2, 2011
}

\begin{abstract}
Two populations of Euphorbia pilosa L. (the Euphorbiaceaea) have been studied meiotically from Kashmir, India. Both the populations uniformly exist at a haploid chromosome count of $n=10$ which was confirmed at various stages of meiosis. The present chromosome count makes an addition to the intraspecific aneuploid cytotypes for the species. Harwan population $(1,900 \mathrm{~m})$ is meiotically normal with good pollen fertility, where as Dachigam $(2,200 \mathrm{~m})$ shows structural hybridity with only $45.61 \%$ pollen fertility. This is the first report of reciprocal translocation in the species.
\end{abstract}

KEYWORDS: Chromosome number, Euphorbia pilosa L., Structural heterozygosity

The state of Jammu and Kashmir, phytogeographically, the most complex and diverse, has a fairly rich diversity of plant life. The area is a store house of numerous medicinal and aromatic plants which grow wild in temperate and alpine habitats. One can find vegetation up to $5,000 \mathrm{~m}$ in the Kashmir area. As part of our programme on exploration of biological diversity in the high altitude plant species, presently, Euphorbia pilosa L. (family, Euphorbiaceae) has been worked out cytologically. It is an erect, $50-90 \mathrm{~cm}$ tall perennial herb with alternate leaves and stems showing branches in the upper region. Its habitat ranges from western Himalaya from Garhwal west wards to Kashmir (Khare 2007). Medicinally the plant is very important as its roots and latex are used as purgative and in the treatment of pistular scores (Chauhan 1999, Bhattacharjee 2004, Pulliah 2006, Khare 2007, Pande et al 2007). It has been used to cure wounds and cuts (Chopda et al 2009, Pande et al 2007). It is known for its skin irritant effects (Kinghorn et al 1975) Due to its limited distribution, it is thought that it should be conserved in India (Bakshi et al 2001).

\section{Materials and Methods}

Materials for meiotic studies were collected from two populations of Euphorbia pilosa L. growing at Harwan and Dachigam area of Srinagar (Kashmir, India) in the month of August 2008. Voucher specimens of the cytologically worked specimens (PUN 55060, 55386) are deposited in the Herbarium, Department of Botany, Punjabi University, Patiala (PUN). The young floral buds were fixed in Carnoy's fixative (6 ethanol: 3 chloroform: 1 acetic acid $\mathrm{v} / \mathrm{v}$ ) for $24 \mathrm{~h}$ and preserved in $70 \%$ alcohol at $4^{\circ} \mathrm{C}$ until use. For meiotic studies, anthers were squashed in $2 \%$ acetocarmine. A number of slides were carefully examined for chromosome counts and meiotic abnormalities at different stages in each population. Pollen fertility was examined using 1:1 glycerol-acetocarmine mixture where well filled pollen grains with stained nuclei were taken as apparently fertile while shrivelled and unstained pollen were counted as apparently sterile (Marks 1954). Photomicrographs of meiotic stages were made from temporary slides using Nikon 80i Eclips Microscope.

\section{Results}

The cytological analysis was made on two populations of E. pilosa which were collected from Harwan and Dachigam areas of Kashmir (India), ranging in altitude from 1,900$2,200 \mathrm{~m}$. The plants of both the populations have a haploid chromosome number of $n=10$. This was confirmed from the presence of 10 bivalents at metaphase-I and diakinesis (Figs 1A and B) and 10:10 chromosome distribution at anaphase I (Fig. 1C). The plants studied from Harwan $(1,900 \mathrm{~m})$ were normal in its meiotic coarse. The PMCs of this accession showed regular bivalent formation and segregation of chromosomes at anaphase I and II. The pollen fertility was quite high $(94.05 \%)$, while the second population growing in Dachigam area $(2,200 \mathrm{~m})$ showed various meiotic abnormalities. As many as $23.87 \%$ PMCs showed the formation of chain among four chromosomes at diakinesis and M-I (Fig. 1 D- F). Un-oriented bivalents were observed at metaphase-II in some PMCs (Fig. 1G). Late disjunction of 1-2 bivalents was also seen (Fig. 1H). At anaphase I and anaphase-II stages of meiosis laggards were also noticed (Fig. 1I-K). The consequences of meiotic abnormalities are quite clear from palynological data. The plants of Harwan population (with normal meiosis) have about $95 \%$ fertile pollen. The plants with structural hybridity showed only $45.61 \%$ pollen fertility and pollen size heterogenosity. Besides the normal sized $(70 \%$; $36.75 \times 34.44 \mu \mathrm{m})$, fertile small sized $(12.06 \%$; $29.15 \mathrm{x}$ $25.86 \mu \mathrm{m})$ and large sized $(17.73 \% ; 45.57 \times 40.31 \mu \mathrm{m})$ pollens were also observed (Fig. 1L).

\section{Discussion}

Euphorbia is reported to show great variability in chromosome numbers and chromosome morphology (Perry 

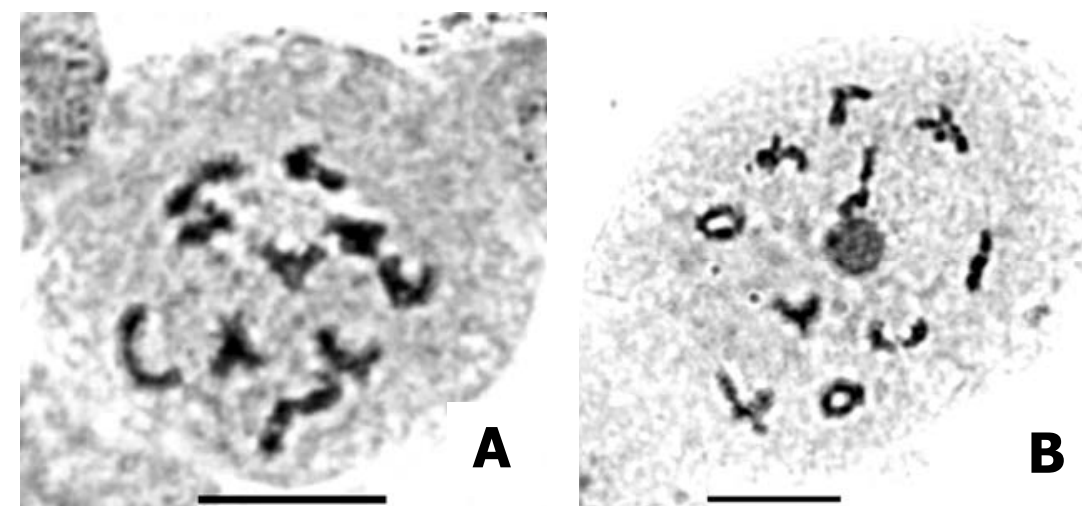

A
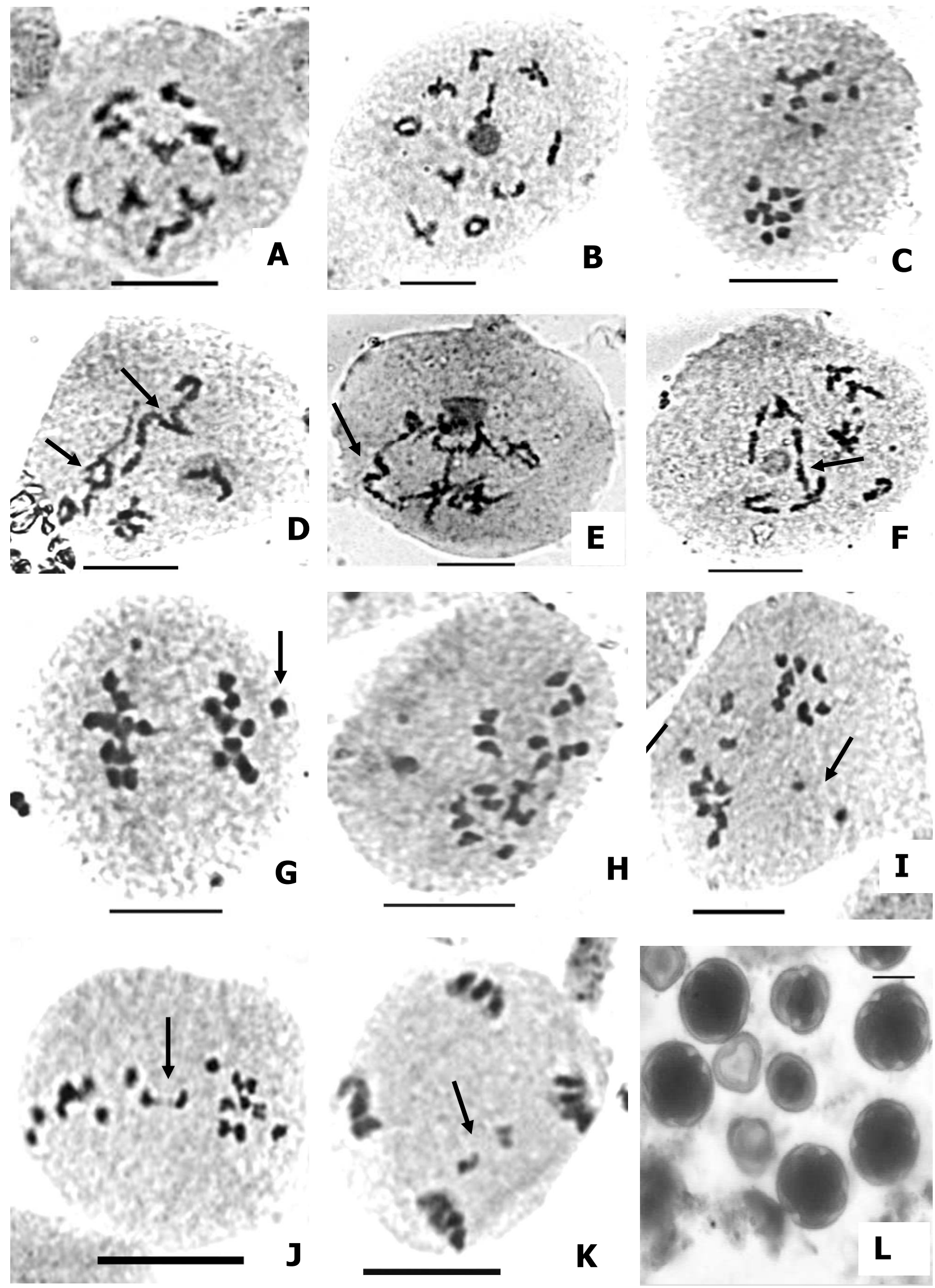

Fig 1. Meiotic chromosomes of Euphorbia pilosa L. $(2 \mathrm{n}=20)$. A. PMC showing $10_{\text {II }}$ at metaphase I. B. PMC showing $10_{\text {II }}$ at diakinesis. C. PMC at anaphase I showing 10:10 chromosome distribution. D-F. PMCs showing chain formation. G. PMCs showing un-oriented bivalent at metaphase II. H. PMC showing late disjunction of 1-2 bivalents. I-K. PMCs showing laggards at anaphase I and anaphase II., L. Heterogenous sized fertile along with sterile pollen grains. Scale=10 $\mu \mathrm{m}$. 
1943). The chromosome numbers reported in the genus are $2 \mathrm{n}=12,14,16,18,20,24,26,28,30,36,40$ and 56 (Federov 1969). The genus is polybasic with $\mathrm{x}=7,10$ as primary base numbers and $\mathrm{x}=6,8$ and 9 as secondary base numbers (Hans 1973).

The present chromosome count of $\mathrm{n}=10$ for E. pilosa makes an addition to the intraspecific aneuploid cytotype for the species. This count is in variance with the previous reports of $2 \mathrm{n}=18$ (Stepanov 1994, Perry 1943) from outside India and 2n=32 (Choda and Mehra 1971, Mehra and Chada 1978) from India. Presently, out of the two populations, plants of one population showed structural heterozygosity (first report of the phenomenon in this species) while the other species had perfectly normal meiosis. Structural chromosomal changes and polyploidy are now considered as important mechanisms for the evolution of plants (Sybenga 1992). Laggards were also observed at different stages which may be due to abnormal spindle formation (Tarar and Dyansagar 1980) or delayed terminalization (Kumar and Tripathi 2007). Any one of or all cytogenetic phenomenon, such as irregular segregation, non-disjunction, unequal translocation, centric fusion, fission and hybridization may be involved in the origin of dysploid chromosome numbers (Stebbins 1971). Pollen grains of heterogenous sizes were formed which may be the consequence of unreduced nature or presence of laggards which later on form micronuclei and reduced pollen fertility $(45.61 \%)$. Carr and Carr $(1983,2000)$ and Levin (2002) have also reported that chromosomal rearrangements and other abnormalities are responsible for reduced pollen fertility in plants. Although the cytological status of these heterogenous sized pollen grains could not be ascertained but the role of small and large sized pollen grains in the production of aneuploid and polyploid plants could not be ruled out, because these pollen grains are apparently fertile.

ACKNOWLEDGEMENTS. The authors are grateful to the University Grants Commission, New Delhi for providing financial assistance under the DRS SAP I and II and ASIST programmes. Thanks are also due to the Director Botanical survey of India (Dehradun) for identification of the species and Head, Department of Botany, Punjabi University, Patiala for necessary laboratory facilities.

\section{Literature Cited}

Bakshi, G., Sarma, S. and Pal, D. C. 2001. A lexicon of medicinal plants in India (vol.2). Naya Prokash. 206 Bidhan Sarani Calcutta 700006, India

Bhattacharjee, S. K. 2004. Hand book of Medicinal plants. Pointer Publishers, Jaipur, India.

Carr, G. D. and Carr, R. L. 2000. A new chromosome race of Calycadenia pauciflora (Asteraceaea: Heliantheae- Medicine) from Butte country, California. Amer. Journ. Bot. 87: 1459-1465.

Chopda M. Z. and Mahajan R. T. 2009. Wound healing plants of Jalgan district of Maharastra state. Ethanobotanical Leaflets. 13: 1-32.

Carr, R. L. and Carr, G. D. 1983. Chromosome races and structural heterozygosity in Calycadenia ciliosa Greene (Asteraceae). Amer. Jour. Bot. 70: 744-755.

Chauhan, N. S. 1999. Medicinal and Aromatic plants of Himachal Pradesh. Indus Publishing Co., New Delhi.

Choda, S. P. and Mehra, P. N. 1971. Cytological studies in some Euphorbiaceae. Curr. Sci. 41:76.

Fedorov, A. N. A, Ed., 1969. Chromosome numbers of flowering plants. Academy of Science of the USSR, Komarov Bot. Inst., Leningrad (Reprint, 1974).

Hans, A. S. 1973. Chromosome conspectus of Euphorbiaceae. Taxon 22: 591-630.

Khare, C. P. 2007. Indian medicinal plants: An illustrated Dictionary. Springer Publications.

Kinghorn, A. D. and Evans, F. J. 1975. A biological screen of selected species of the genus Euphorbia for skin irritant effects. (FDA: U.S. Food and Drug Administration). Planta Med. 28: 325-335.

Kumar, G. and Tripathi, R. 2007. Anomalous nucleolar and chromosomal organization in induced phenodeviants of grasspea. Cytologia 79: 345-350.

Levin, D. A. 2002. The role of chromosomal changes in plant evolution. Oxford Univ. Press, oxford.

Marks, G. E. 1954. An acetocarmine glycerol jelly for use in pollen fertility counts. Stain Tech. 29: 277.

Mehra, P. N. and Chada, S. P. 1978. Cyto-taxonomical studies in the genus Euphorbia L. Cytologia 43: 217-235.

Pande, P. C., Tiwari, L. and Pande, H. C. 2007. Ethno veterinary plants of Utranchal- A review. Indian Journal of Traditional Knowledge. 6: 444-458.

Perry, B. A. 1943. Chromosomes numbers and phylogenetic relationships in Euphorbiaceaea. Amer. Journ. Bot. 30: 527-543.

Pullaiah, T. 2006. Encyclopedia of world medicinal plants (vol2). Regency Publications 20136-Gold Market, West Patel Nagar, New Delhi.

Stebbins, G. L. 1971. Chromosome Evolution in higher Plants. Edward Arnold, London.

Stepanov, N. N. 1994a. Chromosome numbers in some nemoral species of the west Sayan (Krasnoyarsk region). Bot. Zhurm. (St. Petersburg) 79: 125-128.

Sybenga, J. 1992. Cytogenetics in plant breeding. Monographs on theoretical and applied genetics. Springer, Berlin.

Tarar, J. L. and Dyansagar, V. R. 1980. Effect of gamma rays and EMS on growth and branching in Turneria ulmifolia L. Journ. Cytol. Genet. 14: 118-124. 